\title{
Primary primitive neuroectodermal tumor of the cervix: A report of two cases and review of the literature
}

\author{
XIAOFENG WANG $^{1}$, YAN GAO ${ }^{1}$, YANNING XU ${ }^{2}$, YIXIN LIU ${ }^{2}$ and PENGPENG QU ${ }^{1}$ \\ Departments of ${ }^{1}$ Gynecological Oncology and ${ }^{2}$ Pathology, Tianjin Central Hospital \\ of Gynecology and Obstetrics, Tianjin 300100, P.R. China
}

Received April 21, 2016; Accepted November 23, 2016

DOI: $10.3892 / \mathrm{mco} .2017 .1193$

\begin{abstract}
Peripheral primitive neuroectodermal tumor(PNET) of the cervix uteri is extremely rare. Two cases of PNET of the cervix are presented herein. Two female patients, aged 48 and 43 years, presented with irregular uterine bleeding over the course of 1 year, and increased urinary frequency for 1 month, respectively. On gynecological examination, a mass in the cervix was palpated and a biopsy performed. The findings of the initial biopsy revealed small-cell carcinoma in both patients. Following neoadjuvant chemotherapy and radiotherapy, radical hysterectomy was performed in both patients. One patient received 5 courses of consolidation chemotherapy and postoperative radiotherapy, whereas the other patient received 1 course of consolidation chemotherapy. At the time of the article submission, both patients remained disease-free at 27 and 12 months, respectively, after their initial diagnosis. Only a limited number of cases of PNET of the cervix uteri have been reported in the literature to date. Multimodal therapies, including total excision, adjuvant chemotherapy and/or radiotherapy, have been adopted to treat patients with PNET of the cervix.
\end{abstract}

\section{Introduction}

The term primitive neuroectodermal tumor (PNET) was first introduced by Hart and Earle to describe tumors composed of small round cells with different degrees of neural, glial and ependymal differentiation (1). PNETs have been classified according to the World Health Organization as central- and peripheral-type. Central PNETs usually involve the brain and spinal cord, whereas peripheral PNET involve the sympathetic nervous system, skeleton and soft tissues (2).

Correspondence to: Professor Pengpeng Qu, Department of Gynecological Oncology, Tianjin Central Hospital of Gynecology and Obstetrics, 156 Nankai Third Road, Nankai, Tianjin 300100, P.R. China

E-mail: qu.pengpeng@hotmail.com

Key words: primitive neuroectodermal tumor, cervix
PNETs of the cervix are extremely rare. To the best of our knowledge, only 14 cases have been described between 1987 and 2015 in the English literature (3-14) and there are currently no universally accepted standard treatment guidelines. Data on long-term follow-up are not available and the clinical outcome of PNET patients remains elusive (4-6). The aim of this study was to present two cases of primary PNET of the cervix and describe the diagnostic and treatment procedures.

\section{Case reports}

Case 1. A 48-year-old woman, gravida 3, para 2, presented with irregular uterine bleeding over the course of 1 year. On gynecological examination, a cervical mass rich in blood vessels was identified, measuring $6.0 \mathrm{~cm}$ in its greatest dimension (Fig. 1). The left parametrium was also involved, and the tumor was staged as IIb. A cervical biopsy was performed and the initial diagnosis was small-cell carcinoma.

Histologically, the tumor comprised small blue-stained tumor cells with scant cytoplasm, arranged in dense sheets, without rosette or gland formation. Areas of necrosis were present. The neoplastic cells, some of which exhibited prominent nucleoli, infiltrated several capillaries. The cells uniformly expressed CD99 and vimentin, whereas synaptophysin (Syn), CD56, S-100 and epithelial membrane antigen were focally positive. Neuron-specific enolase (NSE), chromogranin A (CgA), cytokeratin (CK), CK5, CK8/18, P16, leukocyte common antigen (LCA), desmin, actin, myogenic differentiation 1 and Wilms tumor 1 were not expressed. The Ki-67 labeling index was $\sim 80 \%$.

The laboratory tests evaluating hematological parameters, electrolyte levels, and hepatic and renal functions, were normal. The levels of tumor markers, including squamous cell carcinoma antigen (SCC), human epididymis protein 4 (HE4), carbohydrate antigen (CA)125, CA199, $\alpha$-fetoprotein (AFP), and $\beta$-human chorionic gonadotrophin $(\beta-\mathrm{HCG})$ were within the normal range. A positron emission tomography-computed tomography scan showed a cervical tumor with abnormally increased metabolism and hypermetabolic lymph nodes in the area of the left iliac vessels.

After one course of induction chemotherapy (pirarubicin + cisplatin + ifosfamide) and internal radiation (iridium-192,17 Gy), the patient underwent radical hysterectomy with bilateral salpingo-oophorectomy and bilateral 

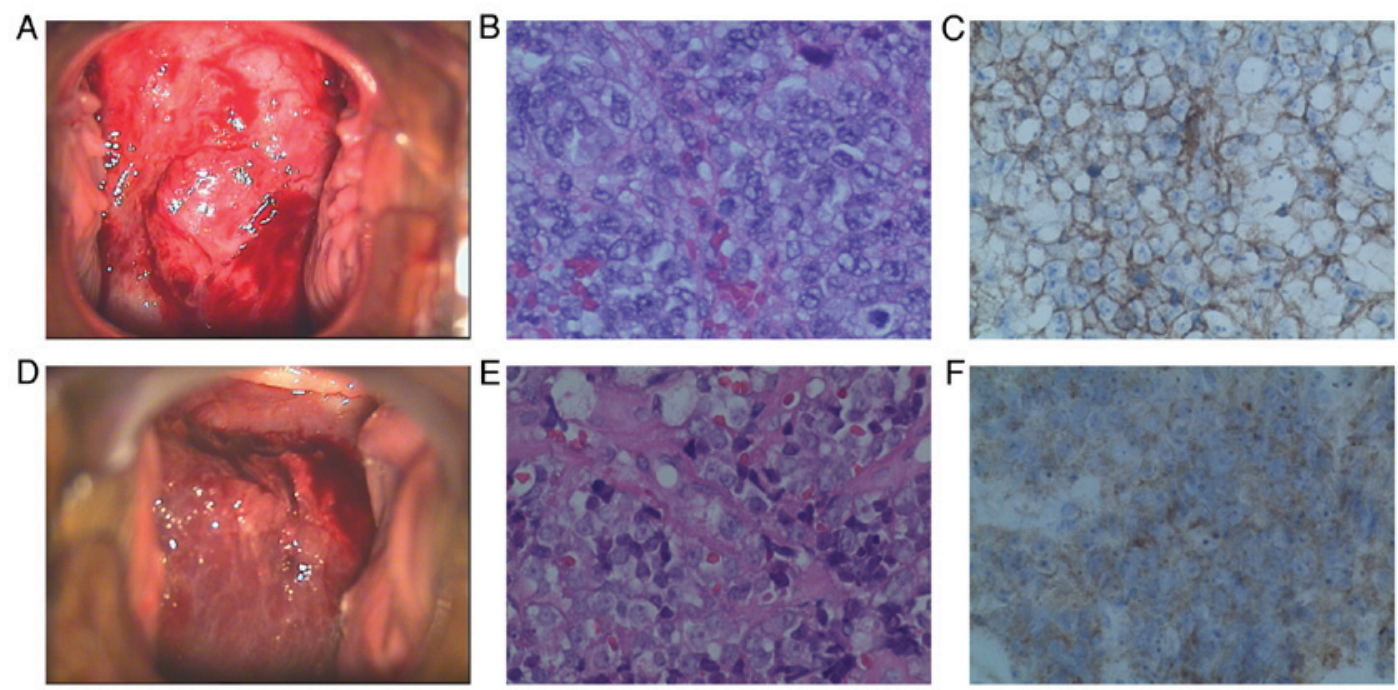

Figure 1. Colposcopic, histological and immunohistochemical examination. Case 1: (A) Image of the cervix on colposcopy; (B) the tumor was composed of sheets of small cells [hematoxylin and eosin (H\&E) staining; magnification, $\mathrm{x} 400$ ]; (C) the tumor cells were positive for CD99 (magnification, $\mathrm{x} 400$ ). Case 2: (D) Image of the cervix on colposcopy; (E) the tumor was composed of sheets of small cells (H\&E staining; magnification, $\mathrm{x} 400$ ); (F) the tumor cells positive for CD99 (magnification, x400).

pelvic lymphadenectomy. The postoperative histopathological examination revealed a tumor embolus in a vessel and involvement of 5 of the 28 lymph nodes. Five courses of consolidation chemotherapy with the previous regimen were completed. The patient also received postoperative radiotherapy with a dose of 200 cGy 5 days per week for 4 weeks.

The patient is currently followed up in our outpatient clinic every 3 months; at the 27 -month follow-up, she remained asymptomatic and clinically disease-free.

Case 2. A 43-year-old woman, gravida 2, para 2, presented with urinary frequency for 1 month. On gynecological examination, a mass was identified in the cervix, measuring $10.0 \mathrm{~cm}$ in its greatest dimension, with left parametrial involvement (Fig. 1). The tumor was staged as IIb. A cervical biopsy was performed and the initial diagnosis was small-cell carcinoma. The patient underwent radical hysterectomy with bilateral salpingo-oophorectomy and lymph node dissection.

Histologically, the tumor consisted of small blue tumor cells with scant cytoplasm arranged in dense sheets, without rosette or gland formation. Areas of necrosis were present. The neoplastic cells, some of which exhibited prominent nucleoli, infiltrated several capillaries (Fig. 1). Some cells had indistinct cytoplasmic borders with vesicular nuclei. Immunohistochemistry confirmed the diagnosis, as the cells expressed the CD99 antigen and were negative for CgA, NSE, Syn, LCA, CK, human melanoma black 45, melan-A, S-100 and P16. The Ki-67 labeling index was $~ 90 \%$.

The fasting blood glucose level of the patient was $11.37 \mathrm{mmol} / 1$. The tumor markers were as follows: SCC $2.4 \mathrm{ng} / \mathrm{ml}$ (normal, $<1.5 \mathrm{ng} / \mathrm{ml}$ ) and HE4 $218.7 \mathrm{pmol} / 1$ (normal, $<140 \mathrm{pmol} / \mathrm{l}$ ). CA125, CA199, AFP and $\beta$-HCG were within the normal range.

After one course of induction chemotherapy (pirarubicin + cisplatin + ifosfamide) and internal radiation (iridium-192, 24 Gy), the patient underwent radical hysterectomy with bilateral salpingo-oophorectomy and bilateral pelvic lymphadenectomy. An accessory ureter was found in the left pelvic cavity. The postoperative histopathological examination revealed no residual tumor. Due to financial difficulties, the patient received only 1 course of consolidation chemotherapy with the previous regimen, and postoperative radiotherapy was not completed.

The patient is currently followed up in our outpatient clinic discontinuously; at the 12-month follow-up, she remained asymptomatic and clinically disease-free.

\section{Discussion}

Peripheral PNET is a rare and aggressive malignancy of the female genital tract. The ovaries are the most common and the uterine corpus the second most common location of PNET $(15,16)$, followed by the cervix $(8)$, vulva and vagina (17). Overall, 14 cases of PNET of the uterine cervix have been reported in the English literature to date, in patients aged 21-51 years (Table I). As previously reported, the main presenting symptoms of cervical PNET are irregular vaginal bleeding, lower abdominal distension and pain, uterine enlargement and a mass increasing in size (16). The incidence of PNET is difficult to ascertain, due to its rarity.

The diagnosis of PNET is difficult by routine hematoxylin and eosin staining alone, due to the overlapping clinical, imaging, histological and immunophenotypic characteristics with other small round-cell tumors, such as primary small-cell tumor, osteosarcoma, non-Hodgkin lymphoma, malignant melanoma and metastases (18). The diagnosis is based on a combination of morphological and immunohistochemical characteristics and electron microscopy. Rosettes are formed from the cytoplasmic extensions in several cases. CD99, a specific immunohistochemical marker for the diagnosis of PNET, is present in $>97 \%$ of the cases (19). In the two cases presented in this study, PNET was strongly expressed on the tumor cell membranes. It has been reported that some tumor cells express vimentin and focally NSE, CgA, Syn, and S-100 (20). Molecular genetic analysis may identify 
Table I. Management of patients with PNET of the cervix.

\begin{tabular}{|c|c|c|c|c|c|}
\hline Authors & $\begin{array}{l}\text { Age, } \\
\text { years }\end{array}$ & $\begin{array}{l}\text { FIGO } \\
\text { stage }\end{array}$ & Treatment & $\begin{array}{l}\text { Follow-up, } \\
\text { months }\end{array}$ & Refs. \\
\hline Sato et al & 44 & $\mathrm{Ib} 2$ & $\mathrm{TAH}+\mathrm{BSO}+\mathrm{PL}+\mathrm{CT}$ & AWD, 6 & (3) \\
\hline Horn et al & 26 & $\mathrm{Ib} 1$ & $\mathrm{TAH}+\mathrm{BSO}+\mathrm{PL}+\mathrm{RT}+\mathrm{CT}$ & DOD, 50 & (4) \\
\hline Cenacchi et al & 36 & $\mathrm{Ib} 2$ & TAH & AWD, 18 & $(5)$ \\
\hline Pauwels et al & 45 & $\mathrm{Ib} 1$ & $\mathrm{TAH}+\mathrm{RT}$ & AWD, 42 & (6) \\
\hline Tsao et al & 24 & NA & $\mathrm{CT}+\mathrm{RH}+\mathrm{CT}+\mathrm{RT}$ & NA & (7) \\
\hline Malpica et al & & & & & (8) \\
\hline Case 1 & 35 & $\mathrm{Ib} 1$ & $\mathrm{TAH}+\mathrm{BSO}+\mathrm{PL}+\mathrm{CT}$ & AWD, 5 & \\
\hline Case 2 & 50 & $\mathrm{Ib} 2$ & $\mathrm{TAH}+\mathrm{BSO}+\mathrm{PL}+\mathrm{CT}$ & AWD, 18 & \\
\hline Snijders-Keilholz et al & 21 & $\mathrm{Ib} 2$ & $\mathrm{CT}+\mathrm{TAH}+\mathrm{CT}$ & AWD, 27 & (9) \\
\hline Farzaneh et al & 45 & $\mathrm{Ib} 2$ & $\mathrm{CT}+\mathrm{RH}+\mathrm{PL}+\mathrm{CT}$ & AWD, 48 & $(10)$ \\
\hline Masoura et al & 23 & $\mathrm{IVb}$ & $\mathrm{TAH}+\mathrm{BSO}+\mathrm{CT}$ & DOD $^{\mathrm{a}}$ & $(11)$ \\
\hline Arora et al & 23 & NA & $\mathrm{CT}+\mathrm{RH}+\mathrm{PL}+\mathrm{RT}$ & AWD, 36 & $(12)$ \\
\hline Li et al & 27 & IIIb & $\mathrm{CT}+\mathrm{RT}$ & AWD, 6 & (13) \\
\hline Xiao et al & & & & & (14) \\
\hline Case 1 & 52 & IIa & $\mathrm{TAH}+\mathrm{BSO}+\mathrm{PL}+\mathrm{CT}+\mathrm{CRS}$ & DOD, 9 & \\
\hline Case 2 & 59 & $\mathrm{IVb}$ & $\begin{array}{l}\mathrm{TAH}+\mathrm{BSO}+\mathrm{PL}+\text { partial small } \\
\text { intestinal excision }\end{array}$ & $\mathrm{DOD}^{\mathrm{b}}$ & \\
\hline \multicolumn{6}{|l|}{ Present } \\
\hline Case 1 & 48 & IIb & $\mathrm{CT}+$ brachytherapy $+\mathrm{RH}+\mathrm{PL}+\mathrm{CT}+\mathrm{RT}$ & AWD, 27 & \\
\hline Case 2 & 43 & $\mathrm{IIb}$ & $\mathrm{CT}+$ brachytherapy $+\mathrm{RH}+\mathrm{PL}+\mathrm{CT}$ & AWD, 12 & \\
\hline
\end{tabular}

chromosome translocations that help distinguish peripheral PNETs from other round-cell tumors. Approximately $85 \%$ of peripheral PNET cases have a balanced $t(11 ; 22)(q 24 ; q 12)$ translocation that results in the formation of a chimerical fusion of the EWS-FLI1 gene (21).

A standard management protocol for this tumor is currently unavailable (22). The treatment strategies for PNET include surgical resection, adjuvant chemotherapy and radiation therapy. Adjuvant chemotherapy was considered to play an important part in PNET management, as the tumors were associated with a 80-90\% relapse rate with surgery alone (23). Radiation therapy has been typically used for patients with inoperable tumors and/or positive surgical margins, and in those with a poor histological response (24). The majority of the chemotherapy regimens reported are based on trials with bone PNETs (25). The commonly used chemotherapeutic agents include cisplatin, vincristine, doxorubicin, ifosfamide, cyclophosphamide, dactinomycin and VP-16, but there is currently no consensus on the optimal chemotherapy treatment. Among the previously reported cases, only 1 patient was treated with chemotherapy and radiotherapy alone; 13 patients were treated with hysterectomy, whereas bilateral salpingo-oophorectomy, with or without pelvic lymphadenectomy, was also performed in a proportion of those patients. Of the 13 patients, 7 were previously reported to receive chemotherapy alone and 1 received radiotherapy alone. In 3 patients, a combination of chemotherapy and radiotherapy was administered postoperatively. In our cases, both patients received neoadjuvant chemotherapy and radiation to reduce tumor burden.

The most unfavorable prognostic factor is the presence of distant metastasis at the time of diagnosis (26). Of the 14 cases reported, 2 stage IVb patients succumbed to the disease soon after diagnosis. Other unfavorable prognostic factors include late-stage disease, insufficient surgical resection, large tumor size, central location of the lesions (pelvis or spine) and poor response to chemotherapy (26).

Overall, peripheral PNET is a rare finding, particularly in the cervix, and requires early detection, correct diagnosis and multimodal therapies, including total excision, adjuvant chemotherapy and/or radiotherapy. The study of more cases of primary peripheral PNET with longer follow-up periods is required to facilitate the formulation of treatment protocols.

\section{Acknowledgements}

The authors wish to thank Editage (http:/www.aje.com/) for the English language editing, and the staff of the Tianjin Central Hospital of Gynecology and Obstetrics, particularly the staff at the Department of Gynecological Oncology. 


\section{References}

1. Hart MN and Earle KM: Primitive neuroectodermal tumors of the brain in children. Cancer 32: 890-897, 1973.

2. Louis DN, Ohgaki H, Wiestler OD, Cavenee WK, Burger PC, Jouvet A, Scheithauer BW and Kleihues P: The 2007 WHO classification of tumours of the central nervous system. Acta Neuropathol 114: 97-109, 2007.

3. Sato S, Yajima A, Kimura N, Namiki T, Furuhashi N and Sakuma H: Peripheral neuroepithelioma (peripheral primitive neuroectodermal tumor) of the uterine cervix. Tohoku J Exp Med 180: 187-195, 1996.

4. Horn LC, Fischer U and Bilek K: Primitive neuroectodermal tumor of the cervix uteri. A case report. Gen Diagn Pathol 142: 227-230, 1997.

5. Cenacchi G, Pasquinelli G, Montanaro L, Cerasoli S, Vici M, Bisceglia M, Giangaspero F, Martinelli GN and Derenzini M: Primary endocervical extraosseous Ewing's sarcoma/PNET. Int J Gynecol Pathol 17: 83-88, 1998.

6. Pauwels P, Ambros P, Hattinger C, Lammens M, Dal Cin P, Ribot J, Struyk A and van den Berghe H: Peripheral primitive neuroectodermal tumour of the cervix. Virchows Arch 436: 68-73, 2000.

7. Tsao AS, Roth LM, Sandler A and Hurteau JA: Cervical primitive neuroectodermal tumor. Gynecol Oncol 83: 138-142, 2001.

8. Malpica A and Moran CA: Primitive neuroectodermal tumor of the cervix: A clinicopathologic and immunohistochemical study of two cases. Ann Diagn Pathol 6: 281-287, 2002.

9. Snijders-Keilholz A, Ewing P, Seynaeve C and Burger CW: Primitive neuroectodermal tumor of the cervix uteri: A case report-changing concepts in therapy. Gynecol Oncol 98: 516-519, 2005.

10. Farzaneh F, Rezvani H, Boroujeni PT and Rahimi F: Primitive neuroectodermal tumor of the cervix: A case report. J Med Case Reports 5: 489, 2011.

11. Masoura S, Kourtis A, Kalogiannidis I, Kotoula V, Anagnostou E, Angelidou $\mathrm{S}$ and Agorastos T: Primary primitive neuroectodermal tumor of the cervix confirmed with molecular analysis in a 23-year-old woman: A case report. Pathol Res Pract 208: $245-249,2012$

12. Arora N, Kalra A, Kausar H, Ghosh TK and Majumdar A Primitive neuroectodermal tumour of uterine cervix - a diagnostic and therapeutic dilemma. J Obstet Gynaecol 32: 711-713, 2012.

13. Li B, Ouyang L, Han X, Zhou Y, Tong X, Zhang S and Zhang Q: Primary primitive neuroectodermal tumor of the cervix. Onco Targets Ther 6: 707-711, 2013.
14. Xiao C, Zhao J, Guo P, Wang D, Zhao D, Ren T, Yang J, Shen K, Lang J, Xiang Y, et al: Clinical analysis of primary primitive neuroectodermal tumors in the female genital tract. Int J Gynecol Cancer 24: 404-409, 2014.

15. Kleinman GM, Young RH and Scully RE: Primary neuroectodermal tumors of the ovary. A report of 25 cases. Am J Surg Pathol 17: 764-778, 1993.

16. Euscher ED, Deavers MT, Lopez-Terrada D, Lazar AJ, Silva EG and Malpica A: Uterine tumors with neuroectodermal differentiation: A series of 17 cases and review of the literature. Am J Surg Pathol 32: 219-228, 2008.

17. McCluggage WG, Sumathi VP, Nucci MR, Hirsch M, Dal Cin P, Wells M, Flanagan AM and Fisher C: Ewing family of tumours involving the vulva and vagina: Report of a series of four cases. J Clin Pathol 60: 674-680, 2007.

18. Yang J, Guo Q, Yang Y, Zhang J, Lang J and Shi H: Primary vulvar Ewing sarcoma/primitive neuroectodermal tumor: A report of one case and review of the literature. J Pediatr Adolesc Gynecol 25: e93-e97, 2012.

19. Vural C, Uluoğlu O, Akyürek N, Oğuz A and Karadeniz C: The evaluation of CD99 immunoreactivity and EWS/FLI1 translocation by fluorescence in situ hybridization in central PNETs and Ewing's sarcoma family of tumors. Pathol Oncol Res 17: 619-625, 2011.

20. Dadhwal V, Bahadur A, Gupta R, Bansal S and Mittal S: Peripheral neuroectodermal tumor of the vulva: A case report. J Low Genit Tract Dis 14: 59-62, 2010.

21. Cetiner H, Kir G, Gelmann EP and Ozdemirli M: Primary vulvar Ewing sarcoma/primitive neuroectodermal tumor: A report of 2 cases and review of the literature. Int J Gynecol Cancer 19: 1131-1136, 2009.

22. Kimber C, Michalski A, Spitz L and Pierro A: Primitive neuroectodermal tumours: Anatomic location, extent of surgery, and outcome. J Pediatr Surg 33: 39-41, 1998.

23. Bose P, Murugan P, Gillies E and Holter JL: Extraosseous Ewing's sarcoma of the pancreas. Int J Clin Oncol 17: 399-406, 2012.

24. Carvajal R and Meyers P: Ewing's sarcoma and primitive neuroectodermal family of tumors. Hematol Oncol Clin North Am 19: 501-525, vi-vii, 2005.

25. Shah JP, Jelsema J, Bryant CS, Ali-Fehmi R and Malone JM Jr: Carboplatin and paclitaxel adjuvant chemotherapy in primitive neuroectodermal tumor of the uterine corpus. Am J Obstet Gynecol 200: e6-e9, 2009.

26. Iwamoto Y: Diagnosis and treatment of Ewing's sarcoma. Jpn J Clin Oncol 37: 79-89, 2007. 